I Universidade Estadual de Campinas (Unicamp), Campinas, SP, Brasil

mariomed@unicamp.br

Mário Augusto Medeiros da Silva'

\title{
SOBRE SIGNO E DESTERRO, DE PEDRO MEIRA MONTEIRO, E OS FUTUROS DOS PASSADOS POSSÍVEIS
}

Monteiro, Pedro Meira. (2015). Signo e desterro:

Sérgio Buarque de Holanda e a imaginação do Brasil.

São Paulo: Hucitec, 284p.

Do meio para o fim dos anos I960, salvo engano, Sérgio Buarque de Holanda passou a se apresentar pública e anedoticamente como o simples "Pai do Chico". A referência ao mais famoso dos seus filhos poderia ser um sinal de modéstia risonha ou o reconhecimento de que uma nova forma de lidar com a presença de alguns intelectuais no espaço público brasileiro, especialmente os artistas da música brasileira cada vez mais, a partir de então, mediados pela publicidade de massa e alguma devoção - colocava em ocaso tipos como o dele, talhado em outro momento da história social e cultural do país.

Porém, se "o pai do Chico" assim se apresentava, a recíproca talvez tenha demorado muito tempo para ser pública e verdadeira e, quiçá, nem tenha sido. Chico Buarque de Holanda não se apresenta publicamente como "o filho do Sérgio". E como nota Pedro Meira Monteiro, sociólogo e docente na Princeton University, em "Num fiapo de tempo: Chico, Sérgio e Benjamin", capítulo de Signo e desterro: Sérgio Buarque de Holanda e a imaginação do Brasil, há qualquer coisa de ausência constante dessa figura paterna na obra do filho, que se recupera, talvez, nos esforços literários do filho escritor. Essa distância do pai também já havia sido mencionada no documentário Raízes do Brasil (2004), de Nelson Pereira dos Santos, por todos os filhos, valorizando, aliás, o papel da mãe, Maria Amélia, na vida pública e intelectual do pai e da prole dos Buarque de Holanda.

Esses detalhes mencionados permitem percorrer um grande arco tempo- 
ral tendo a figura de Sérgio Buarque como guia e ajudam a enfeixar um duplo problema, suscitado pela leitura de Signo e desterro: I) de um lado, o que de novo pode haver em revisitar a obra de Sérgio Buarque de Holanda? 2) decorrência disso e dos dias que vivemos, há algo a ser dito sobre a presença e a obra dos intelectuais na vida pública hoje?

Entre "o pai do Chico" e "o filho do Sérgio" - esta última expressão é minha - decorrem-se em Signo e desterro nove capítulos divididos em três partes ("Política familiar", "O inexistente americano" e "A palavra e o tempo") com uma imersão na obra mais conhecida e controversa do pai, sociólogo e historiador. E como assinala Meira Monteiro, Raízes do Brasil se mostraria um livro incômodo para Sérgio Buarque, que com ele teve que se haver na labuta da mudança dos tempos, entre I 936 e sua versão definitiva, de I956. O tempo e as tomadas de posição, bem como as críticas e os espaços percorridos pelo autor, lhe exigiram reescrita, precisões, supressões e defesas, num intervalo de preocupações anteriores, que começa com um jovem de menos de 20 anos lançado no espaço de realização por excelência do intelectual, - o jornal, o tradicional Correio Paulistano - passando pelo ofício da crítica literária sob os influxos do Modernismo de I922, alcançando-o posteriormente como o autor de Raízes do Brasil na casa dos trinta anos.

Mas a gravitação da obra e de suas afirmações sobre o Brasil, nossa formação, a então hora presente e os apontamentos para o futuro tiveram de ser debatidos e retomados até o momento da conversão em "Dr. Sérgio", professor catedrático de história da civilização brasileira na Universidade de São Paulo, já um tanto distante daqueles anos I930, entremeado por obras de, para alguns, maior rigor, envolvido na institucionalização universitária que não marcou sua formação. Essa conversão se dá sob as críticas da forma ensaio da qual fora praticante e, dali a um tanto, convertido na curiosa figura de pai do Outro Buarque de Holanda nos anos I960 - algo que aparece no interessante capítulo do livro, "Sérgio Buarque de Holanda e as palavras (evocação de Wittgenstein)".

Em meio àqueles nove capítulos e um epílogo (denominado "Raízes do século XXI: Wisnik e o horizonte do ensaio"), entretanto, também se passa o tempo. E vale recordar o que novamente suscita Meira Monteiro: o tempo, na forma ensaio, é ponto de fuga (insular, na metáfora da ilha, que o autor emprega), porque não se atreve à precisão, mas quer dizer algo a respeito do passado sobre o qual se debruça (por exemplo, as matrizes ibéricas e o fantasma colonial brasileiro), acerca do presente em que se encontra (um entreguerras mundiais, um intervalo democrático interrompido nacionalmente) e se arrisca, como poucos, a dizer algo sobre a direção do futuro, para onde esvai a matéria, no caso, o sentido desta nação. Vale recordar: Raízes do Brasil é sobre o Brasil, e o devir que ele se arrisca a tratar talvez possa ser este aqui e por décadas agora, o nosso - aliás, pronome possessivo e sem equívocos com o qual Buarque de Holanda encerra sua 
obra, no capítulo intitulado "Nossa revolução".

A passagem do tempo soa, portanto, algo desafiadora na forma do ensaio por seu poder de trafegar entre o passado e fixar pontes no futuro. Ela testa simultaneamente o acerto dos argumentos e a vitalidade analítica do ensaísta. E, se for correto que o futuro sugerido na parte final de Raízes do Brasil nos alcança, pelo menos na última versão do livro, o debate sobre o tema da democracia e as dificuldades de convivência com a ordem dos contrários na vida social brasileira parecem ser terrivelmente atuais na nossa hora presente, no intervalo entre 2014 e 20I6, distante 80 anos da formulação original. O teste do tempo para Raízes é o teste social da realidade para o Brasil e também para sugerir atualidade em Sérgio. De outro lado, voltando à discussão da passagem do tempo, Pedro Meira Monteira reforça e demons tra com maestria que a forma ensaio é prismática, e sua luz se refrata em direções várias.

Apostando nisso, o autor conecta os anos 1930 às primeiras décadas do século XXI e vai além, operando com Sérgio Buarque de Holanda como personagem de um longo século XX brasileiro e seus impasses culturais e políticos. Essa personagem é analisada do ponto de vista das mudanças biográficas, intelectuais e institucionais (na universidade), conectando sua trajetória com as do Brasis coetâneos. Por outro lado, se Sérgio Buarque deixa de dizer algo explícito, fisicamente, em I982, ao falecer, Meira Monteiro então avança para sua obra que, na escrita crítica do sociólogo de Princeton, não cessa de falar. Raízes do Brasil, entre I936 e I956, nessa leitura, arrisca falar sobre todo o século XX e avança para o próximo século como ensaio de interpretação que não se equivoca em dizer algo sobre o movimento não linear e muito sinuoso que é a história brasileira. Meira Monteiro aposta tanto nisso, que aproxima a obra de Sérgio Buarque de Holanda, ao final do seu texto, daquilo que ele chama de "Raízes do Brasil do século XXI".

Nesse sentido, Signo e desterro consegue esmiuçar autor e obra em diálogo com as recepções de Raízes do Brasil (a começar por uma das mais famosas, o prefácio consagrador de Antonio Candido, já nos anos I960, discutido no capítulo "Situando a partida"); o retorno do embate entre o público e o privado (ou uma releitura de Meira Monteiro da releitura de Buarque de Holanda da tragédia Antígona, expresso em "Uma tragédia familiar"); a convivência curiosa e difícil pelos anos com o ensaio-irmão Sobrados e mucambos, de Gilberto Freyre (publicado também em I936, como analisa Meira Monteiro em "Raízes rurais da família brasileira"), a quem Buarque de Holanda, como sugere seu estudioso, procura criticar décadas depois, longe do lugar de ensaísta dos anos I930 que ele fora, mas já como "cientista" da História nos anos I950, numa espécie de ataque-defesa.

Meira Monteiro percorrerá a própria noção de significado linguístico e a sua implicação no entendimento de Brasil e de uma obra que, desde o título, se força a pensar sobre aquele signo (debatido no capítulo denominador, "Sig- 
no e desterro"); as relações com a ideia de América Latina, lida por Meira Monteiro na chave do pensamento social caribenho e ao sul do Grande Irmão (destacados em "Buscando América" e "El hombre cordial”); o embate crítico e ácido de Sérgio com seus contemporâneos dos anos I970, em particular com Carlos Guilherme Mota, em que esgrima pela defesa da sua obra mas também por um certo tipo de historiador que paulatinamente deixava de existir, no já mencionado "Sérgio Buarque de Holanda e as palavras". Curioso que o penúltimo texto do livro de Meira Monteiro, "Num fiapo de tempo", seja justamente sobre uma aproximação da obra de filho e pai, cujo encontro nas letras se revele tão somente como uma possibilidade distante exterior, mediada pela biblioteca paterna e as memórias íntimas do filho, mas distanciada pela passagem e mudança do tempo público para ambos os intelectuais.

Contudo, voltando ao tempo na forma ensaio, creio que há dois pontos ainda a assinalar, que são suscitados por Pedro Meira Monteiro e ajudam a responder algo sobre a atualidade do debate que ele nos propõe a partir de Raízes do Brasil. Um dos capítulos, que atinge o pico em pontos já altos, é dedicado a pensar as possibilidades de rever Entreatos (2004) e Peões (2004) documentários de João Moreira Salles e Eduardo Coutinho - à luz de Raízes do Brasil. Em "Cordialidade e poder: entre o cinema e o ensaio, Lula e a política", aquela ideia do tempo futuro na forma ensaio ganha características distintivas. São os anos do primeiro governo Lula (2002-2006) que se enfocam; é a personagem Luís Inácio que se enquadra, no passado (confrontado pelas memórias dos peões do ABC operário) e seu então presente (dos dias que antecedem sua eleição à Presidência da República, de um lado; mas de outro, no inferno que mergulhava quando do escândalo de corrupção em seu primeiro governo, época de lançamento dos filmes).

Sugiro algo mais: com a inserção desse capítulo em Signo e desterro e sua análise fina, por conta da hora presente em que ele é publicado, não só os problemas da cordialidade, da conciliação e dos embates entre ordem pública, privada e privatismo - temas clássicos da obra dos anos I930 - entram em jogo, mas também um futuro do pretérito composto do capítulo "Nossa revolução" de Raízes do Brasil, num arco histórico que vai de 1936 a 2016. Se a personagem e seu partido não tivessem errado - como é o medo de base sociológica que Lula pronuncia em Entreatos - talvez teríamos, poderíamos ter dado certo em determinada direção. O que, como lembra Meira Monteiro, parecia anunciar que, talvez, naqueles anos, finalmente teríamos lugar num certo mundo teleologicamente avançado, civilizado e desenvolvido. Um futuro do pretérito demasiado duro é este tempo do ensaio.

Mas o autor de Signo e desterro capítulos antes já se mostrara desconfiado da ideia de telos e o quanto isso também seria uma leitura complicada para Raízes do Brasil. Assim, o ato fundador do Partido dos Trabalhadores, no qual Sérgio Buarque assina na primeira linha, é uma aposta que pode ser 
circunscrita a um presente do início dos anos I980. Parece então que ali não se encontra o ensaísta ou o historiador. Mas antes um exemplo do que Antonio Candido, no prefácio e post-scriptum consagrador chamou de radicalismo de classe média. Nada mais deslizante e ambíguo que ser radical de classe média. E talvez são igualmente adjetivos a acrescentar à significativa obra e trajetória de Raízes do Brasil. Como também, "deslizante e ambígua", são características a serem atribuídas à história do Brasil e ao nosso tempo presente, de agora.

Suscitei algo acima sobre o futuro do pretérito. Mas é um tempo diferente com o qual Pedro Meira encerra seu livro. Signo e desterro fecha suas páginas com o futuro, seja sobre os projetos de seu autor ("Conclusão: desdobramentos", em que anuncia uma agenda de pesquisa biográfica sobre Sérgio Buarque) ou se questionando sobre a forma "ensaio de interpretação nacional" e as possibilidades de sua redescoberta, por exemplo em Veneno remédio de José Miguel Wisnik (2008), para Meira Monteiro, o "Raízes do Brasil do Século XXI". A linha do futuro, tanto quanto as de um campo de futebol, divisa um horizonte para a forma, mas também sobre as possibilidades de interpretação do país. São linhas, na minha leitura, otimistas, especialmente por mergulhar na ideia do futebol como o espaço de vitória não do mais perfeito nem do mais forte ou do acúmulo de pontos positivos. Nesse espaço do imponderável, da possibilidade de marcar um gol no último segundo de um jogo, na maior parte do tempo, miserável, mora a vitória na várzea ou no Campeonato Brasileiro e a consagração, seja de um ordinário volante anônimo convertido em herói ou de um Estado Nacional, na contradita dos prognósticos históricos e sociológicos sobre a sua formação social. A nossa "resistência ao retilíneo" (uma ilusão histórica) está na mesma proporção da "vocação não linear do futebol" (uma realidade concreta) e aí reside algo com potência. É uma imagem ousada e tanto para pensar, com a qual o autor nos provoca e instiga a leitura.

Recebida em 2/5/2017

Aprovada em I6/8/2017
Mário Augusto Medeiros da Silva é professor do Departamento de Sociologia do Instituto de Filosofia e Ciências Humanas da Universidade Estadual de Campinas (IFCH-Unicamp). 